\title{
PERFIL DO CONSUMIDOR DE PRODUTOS ORGÂNICOS NA CIDADE DE SÃO JOAQUIM DA BARRA / SP
}

\author{
LIMA, Priscila Aparecida Lemes de ${ }^{1}$ \\ BRUNINI, Maria Amalia ${ }^{2}$ \\ KANESIRO, Lidiane Aparecida ${ }^{3}$ \\ KANESIRO, Janaína Cristina ${ }^{4}$ \\ MACIEL JUNIOR, Vinícius Antônio ${ }^{5}$ \\ COLOMBO, Rangel Brandão ${ }^{6}$
}

\begin{abstract}
RESUMO: Em nome de uma melhor qualidade de vida, as pessoas estão mudando seus hábitos alimentares e se preocupando mais com saúde, meio ambiente e também buscando por alimentos considerados mais saudáveis, onde se incluem os produtos denominados "produtos orgânicos", ou seja, produtos produzidos através de sistema orgânico. Este trabalho relata o perfil do consumidor e potencial consumidor de produtos orgânicos na cidade de São Joaquim da Barra/SP. Foram utilizados para o presente estudo, 74 questionários compostos de 19 questões entre abertas e de múltipla escolha que abordavam temas como idade, sexo, renda familiar, se consome ou não alimentos orgânicos, se ouviram falar sobre produtos orgânicos, se é fácil ou não encontrá-los, porque consomem, entre outros itens abordados. Os resultados evidenciaram que o perfil do consumidor de produtos orgânicos é predominantemente mulher, independente do grau de escolaridade e da classe social, que estão em busca de uma melhor qualidade de vida, preservação da saúde e por busca de um alimento mais saboroso. No geral, pode-se concluir que existe um mercado promissor para os produtos orgânicos que pode ser mais explorado através de maior divulgação, comercialização e preço final do produto.
\end{abstract}

Palavras-chave: Produtos orgânicos. Perfil. Consumidor. Comportamento.

\section{CONSUMER PROFILE OF PRODUCTS ORGANIC IN SÃO JOAQUIM DA BARRA CITY, SAN PAULO STATE}

SUMMARY: On behalf of a better quality of life, people are changing their eating habits and condemning more with health, environment and also seeking food considered healthier, which include products known as "organic", or is, products produced by organic system. This work reports the profile of the consumer and potential consumer of organic food in the city of São Joaquim da Barra/SP. Were used in the present study, 74 questionnaires compounds 19 issues between open and multiple choice, that issues such as age, gender, family income, if consumes or not a organic food, and heard on organic products, if is easy or not find-them, why they consume, among other items discussed. The results showed that the profile of the consumer of organic products is predominantly women, independent of schooling and social class, are in search of better quality of lif,

\footnotetext{
1 Acadêmica do curso de Ciências Biológicas da Faculdade de Filosofia Ciências e Letras de Ituverava, Fundação Educacional de Ituverava- FE. Rua Coronel Flauzino Barbosa Sandoval, 1259, Ituverava (SP) CEP 14500-000. E-mail: prilemeslima@hotmail.com

${ }^{2}$ Professora Adjunto Aposentada da Faculdade de Ciências Agrárias e Veterinárias, Campus de Jaboticabal/ UNESP, e Professora Doutora da Faculdade de Filosofia Ciências e Letras/ FE e da Faculdade dr. Francisco Maeda/ FE. Rua Coronel Flauzino Barbosa Sandoval, 1259, Ituverava (SP) CEP 14500-000. brunini@feituverava.com.br

${ }^{3}$ Professora Mestre da Faculdade de Filosofia Ciências e Letras, Fundação Educacional de Ituverava- FE. Rua

Coronel Flauzino Barbosa Sandoval, 1259, Ituverava (SP) CEP 14500-000.

${ }^{4}$ Mestre em Turimo e Hotelaria

${ }^{5}$ Professor Mestre da Faculdade Dr. Francisco Maeda/ FE. Rua Coronel Flauzino Barbosa Sandoval, 1259, Ituverava (SP) CEP 14500-000.

${ }^{6}$ Engenheiro de Produção
} 
preservation of health and search for a food more tasty. In general, may conclude that exist a promising market for organic products, that may be explored through greater dissemination, marketing and final price of the product.

Keywords: Organic Products. Profile. Consumer. Comportament. Behavior.

\section{INTRODUÇÃO}

Em nome de uma melhor qualidade de vida, as pessoas estão mudando seus hábitos alimentares e consequentemente buscando por alimentos considerados mais saudáveis, onde se incluem os produtos denominados "produtos orgânicos" 7 , ou seja, produtos produzidos através de sistema orgânico.

A produção de alimentos orgânicos vem sofrendo uma forte expansão no Brasil e em outros países como os EUA, Japão, Austrália e outros da América do Sul bem como do continente Europeu (WILLER; YOSSEF, 2006). Segundo estes mesmos autores, este aumento na produção está associado à elevação dos custos da agricultura convencional, degradação do meio ambiente e exigência dos consumidores por produtos considerados saudáveis. Segundo Karam; Zoldan (2004), este aumento está relacionado com sociedades de maior desenvolvimento econômico e social, onde é forte a concentração urbana e a procura por tais produtos, também, é maior.

Apesar do aumento na procura de produtos orgânicos, o mesmo está restrito a uma pequena parte da população, devido seu preço ser mais elevado em relação aos produtos obtidos em sistema tradicional, e por vários países terem grande parte de sua população abaixo da linha de pobreza (STEFANO et al., 2008). Segundo estes mesmos autores, para que ocorra uma maior procura por produtos orgânicos há necessidade de um aumento de renda da população, além da conscientização do consumidor sobre os benefícios do alimento orgânico. Ormond et al. (2002) relata que está ocorrendo uma elitização em relação ao consumo de produtos orgânicos e, consequentemente, uma exclusão dos consumidores de baixo poder aquisitivo.

Logo, o presente trabalho procurou verificar o perfil dos consumidores sobre produtos orgânicos na cidade de São Joaquim da Barra/ SP.

\section{CONSUMIDORES VERSUS ALIMENTOS ORGÂNICOS}

De acordo com Stefano et al. (2008), o comportamento do consumidor é um tema chave para o mercado, com relação a promover e vender produtos. Desta forma, é

\footnotetext{
${ }^{7}$ Os produtos orgânicos são provenientes do sistema orgânicos de produção, que é um sistema de produção que excluem o emprego de fertilizantes e pesticidas nas operações de cultivo.
} 
necessário que o mercado procure entender os desejos e as necessidades dos consumidores de produtos alimentícios, onde se incluem os produtos orgânicos e, consequentemente, possam ampliar as vendas.

O consumidor de alimentos orgânicos como dos demais alimentos, sofre influências de vários fatores, onde se podem citar culturais (fator que mais exerce influência sobre o comportamento do consumidor), sociais, individuais e psicológicos (motivação, percepção, aprendizagem, crenças e atitudes). É estimulado também pelo ambiente externo onde se situa o âmbito econômico, tecnológico e político além de estímulos do setor de marketing. (STEFANO et al., 2008)

As informações a serem adquiridas pelos potenciais consumidores de produtos orgânicos são importantes na hora em que decidem optar pela alimentação orgânica (RUCINSKY; BRANDENBURG, 2000). Acontecimentos mundiais que quando ocorrem e são divulgados na mídia também, influenciam o consumidor, onde pode se citar a doença da vaca louca, alimentos contaminados, entre outros, faz com que o consumidor dê mais importância para sua alimentação (FRANCISCO et al., 2009).

Segundo Rucinsk; Brandenburg (2000), o consumidor orgânico está consciente das incertezas científicas e dos riscos que os agrotóxicos podem causar à saúde humana e percebe que os alimentos orgânicos tornam-se a melhor prevenção de algumas doenças futuras, como as oriundas dos alimentos. Ainda, segundo estes mesmo autores, os consumidores orgânicos dão importância a outros valores como o beneficio coletivo, tendo um estilo de vida que não tem como prioridade o consumismo.

Segundo Shultz et al. (2002), os potenciais consumidores de produtos orgânicos são conquistados pela confiança nos produtores e também pelas mudanças de padrões quanto às questões ambientais, à alimentação, hábitos de vida, saúde, originária em grande parte, pelas descobertas científicas das funcionalidades dos alimentos na vida das pessoas. Segundo Archanjo et al. (2001) dentre os consumidores de produtos orgânicos estão aqueles que se preocupam com a saúde e aqueles que preferem o sabor dos orgânicos, mais não tem como preferência o beneficio a saúde do corpo.

Apesar da alimentação moderna estar mudando os hábitos das pessoas, devido à redução de tempo e trabalho gasto com o preparo das refeições, os consumidores de alimentos orgânicos preferem preparar seus próprios alimentos mesmo que gaste mais tempo em tal atividade, o que mostra que esses consumidores têm idéias e atitudes diferentes perante as transformações alimentares atuais (ARCHANJO et al., 2001). 


\section{PRODUÇÃO DE PRODUTOS ORGÂNICOS}

A agricultura orgânica não se restringe em apenas substituir os fertilizantes químicos por compostos orgânicos ou pesticidas por controle biológico de pragas. Para uma boa produção orgânica o agricultor precisa conhecer bem o ecossistema para um bom manejo do solo e utilizar dos recursos naturais, e manter uma harmonia com a natureza, pois os alimentos têm um ciclo que precisa ser obedecido (ARCHANJO et al., 2001).

A produção e o consumo de alimentos orgânicos fazem parte de uma mudança no comportamento alimentar que, conseqüentemente, auxilia na educação ambiental além de que a agricultura orgânica é considerada uma agricultura sustentável, pois se destaca pelo respeito ao meio ambiente e à humanidade (MOMESSO et al., 2009). Através desta perspectiva, a agricultura orgânica pode ser entendida como um sistema que envolve vários fatores, tais como, solo, minerais, microorganismos e o homem, que se interagem de forma coerente (SOUZA et al., 2000).

O mercado de produtos orgânicos no Brasil ainda é um nicho, pois o preço proveniente de uma oferta descontínua prejudica o crescimento das vendas (SOUZA et al., 2000), e são os pequenos produtores que são responsáveis por $70 \%$ da produção de produtos orgânicos no país (DAROLT, 2001).

Darolt (2003) cita que é preciso melhorar a eficiência logística, diminuindo custos de transporte e de mão-de-obra, negociar baixa do percentual dos supermercados, aumentarem a eficiência nas vendas e aperfeiçoar o relacionamento com os agricultores e os consumidores fazendo com que a procura por alimentos orgânicos aumente, pois através dessas medidas o preço final do produto será menor e acessível à população.

Segundo Cuenca et al. (2007), apesar dos preços elevados os produtos orgânicos tem uma forte aceitação por parte do consumidor.

No Brasil a produção orgânica ocupa 880.000 hectares, o que o torna o segundo maior produtor de orgânicos do mundo, sendo que $70 \%$ de sua produção são para o mercado externo (PEREIRA et al., 2008; FOLHA, 2009). Entretanto, segundo Darolt (2001), o sistema de produção orgânica carece de organização, falta de planejamento de demanda, o que faz com que haja restrição da oferta e obstáculo para os produtores.

Os produtos orgânicos brasileiros comercializados incluem frutas e legumes frescos, nozes e frutas secas, especiarias, ervas, frutas e vegetais processados, cacau, óleos vegetais, doces, alimentos processados e sucos a base de frutas. Itens não alimentares incluem algodão, óleos essenciais para cosméticos e flores de corte (STEFANO et al., 2008).

De acordo com Stefano et al. 2008, a região sudeste brasileira comercializa verduras, ervas, temperos, café, cana-de-açúcar, frutas, pecuária, cosméticos, derivados de soja e 
bebidas, enquanto que, no Sul são comercializados grãos, ervas e temperos, café, frutas, pães, doces e compotas, erva-mate, pecuária, óleos essenciais, a região Nordeste frutas, grãos, café, cacau, guaraná, pecuária e poucas variedades de verduras, Centro-Oeste, carne, grãos e verduras e a região Norte, borracha, guaraná, ervas e temperos, grãos, frutas, óleo de palma e de babaçu.

\section{METODOLOGIA}

Devido ao objetivo principal deste trabalho que é estudar o perfil dos consumidores de produtos orgânicos da cidade de São Joaquim da Barra/ SP, a pesquisa realizada se caracteriza como uma pesquisa aplicada e conclusiva-descritiva. Conclusiva por ser uma pesquisa formal, estruturada e representativa, e descritiva, pois descreve e avalia características dos consumidores entrevistados. A análise descritiva, segundo Malhotra (2001), é a descrição das variáveis analisadas em termo de freqüência, cujo objetivo é transformar informações difusas de uma maneira simples.

O trabalho foi dividido em duas etapas. Inicialmente foi realizado um levantamento exploratório através da aplicação de questionários contendo 19 perguntas entre abertas e de múltipla escolha, junto aos clientes, de quatro supermercados na cidade de São Joaquim da Barra/SP, consumidores de produtos orgânicos e potenciais consumidores de tais produtos. Foram aplicados 74 questionários as pessoas que realizavam suas compras e que se dispusessem a respondê-lo, independendo da idade e sexo, mas que fossem representativas do publico alvo. Dos 74 questionários entregues obteve-se o retorno de $100 \%$ deles.

O questionário era composto de informações relacionadas aos aspectos idade, sexo, grau de escolaridade, renda, estado civil, se a pessoa sabe o que é um produto orgânico, se se preocupam com a sua própria alimentação e a de seus familiares, se ouviu falar e se consome produtos orgânicos, entre outras questões. Além destes itens o questionário procurou obter comentários de natureza subjetiva e impressões pessoais acerca de produtos orgânicos. Antecedendo a aplicação dos questionários foi solicitada oficialmente autorização prévia dos gerentes dos supermercados, e somente após é que foi iniciada a aplicação dos questionários.

A segunda etapa foi o levantamento de dados secundários como pesquisa bibliográfica, pois a fundamentação teórica se baseou em material publicado em artigos científicos, livros e internet.

Os dados obtidos foram codificados, dispostos em planilha eletrônica em forma de banco de dados (Excel for Windows), distribuídos em gráficos e analisados qualitativa e quantitativamente. 


\section{ANÁLISE DOS RESULTADOS}

Os resultados obtidos neste estudo estão apresentados em gráficos, sendo comentados de acordo com os tópicos principais.

\section{Perfil dos entrevistados}

Analisando-se os dados da Figura 1, verifica-se que entre os entrevistados, 57\%, são do sexo feminino, o que mostra uma predominância de mulheres entre os consumidores ou potenciais de produtos orgânicos. Os valores aqui obtidos são coerentes com as verificados por Darolt (2004) em estudo realizado em Curitiba/PR e por Cerveira; Castro (1998) em estudos realizados em São Paulo/ SP, e também com os obtidos por Francisco et al. (2009) em estudo realizado em São Paulo que mostra que 71,2\% dos consumidores são mulheres.

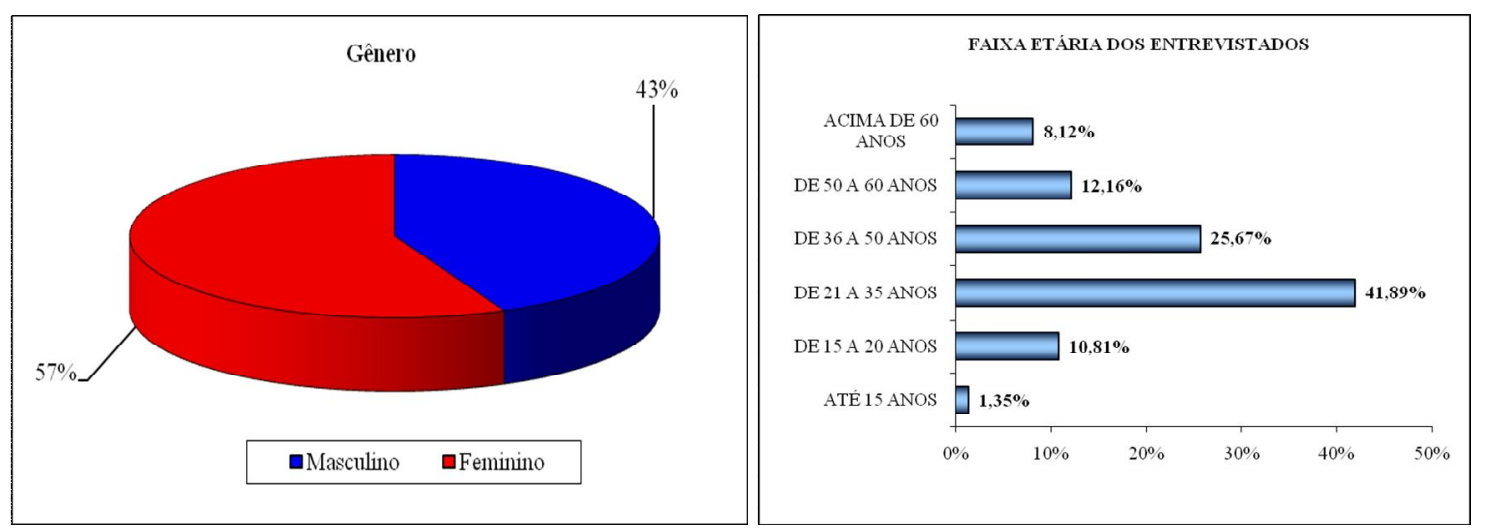

Figura 1: Gênero e faixa etária dos entrevistados.

Com relação à faixa etária, através da Figura 1 pode-se verificar que 41,89\% estão entre 21 e 35 anos seguidos por 25,67\% entre a faixa etária de 36 a 50 anos, o que mostra que a amostragem foi composta por um público mais maduro e com isso estabelecesse outras perspectivas com relação a uma alimentação saudável, e também por terem tido a oportunidade de vivenciarem uma época em que se consumiam alimentos mais naturais.

\section{Grau de escolaridade e estado civil}

Quanto ao grau de escolaridade pode-se verificar que do total entrevistados, $31 \%$ tem curso superior incompleto, $8 \%$ segundo grau incompleto e 19\% segundo grau completo (Figura 2). O perfil aqui obtido não se assemelha ao obtido por Cerveira; Castro (1998) em estudo realizado em São Paulo/SP e por Cuenca et al. (2007) no Rio Grande do Norte e ao Francisco et al. (2009) em estudo realizado em São Paulo onde observou que a maioria dos entrevistados possuam nível superior completo ou pós graduação.

Com relação ao estado civil, pode-se observar que 41,9\% eram solteiros e 39,19\% 
casados, o que mostra que também os solteiros se preocupam com a sua qualidade de vida e saúde (Figura 2).
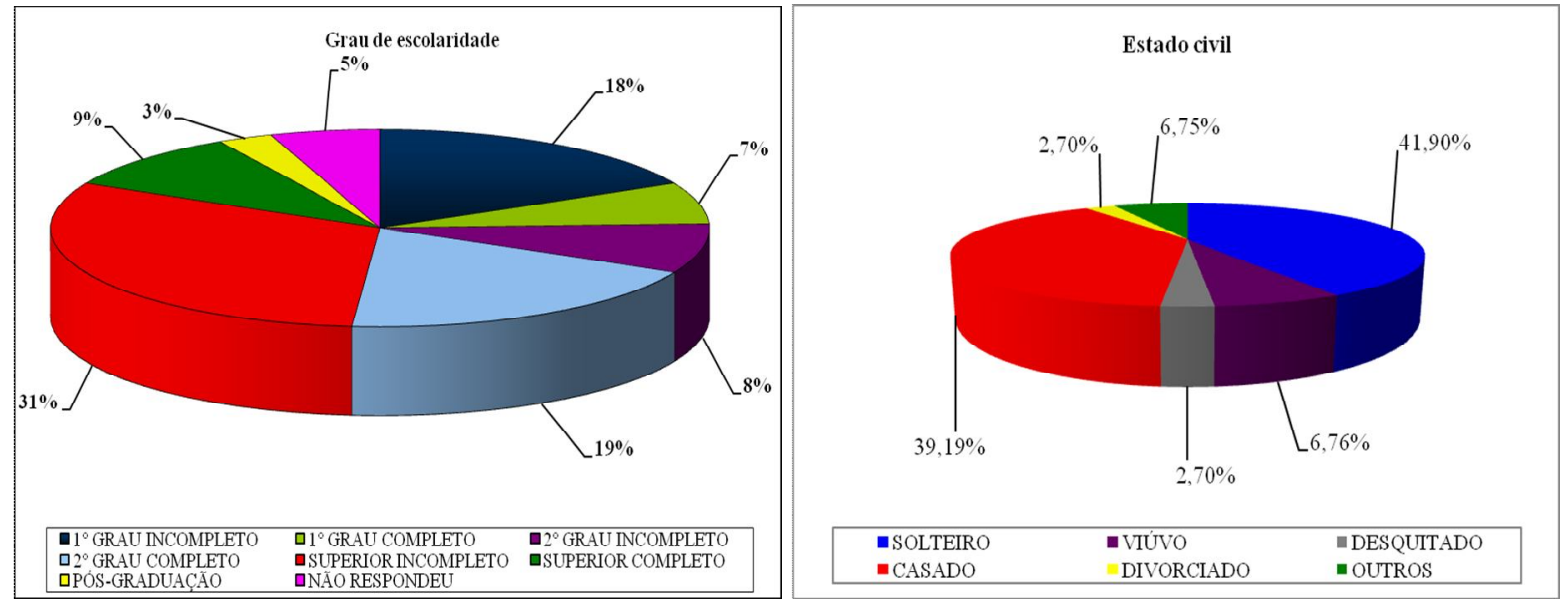

Figura 2: Grau de escolaridade dos entrevistados e estados civil.

\section{Renda Familiar}

Conforme os dados coletados relacionados à renda familiar (Figura 3), pode-se verificar que 43,24\% dos entrevistados responderam que tem renda mensal entre 1 a 3 salários mínimos, 29,74 \% entre 4 a 5 salários mínimos, 17, 5\% entre 5 e 10 salários mínimos, 5,4\% entre 10 e 20 salários mínimos e 1,35\% acima de 20 salários mínimos, o que mostra que o consumo de produtos orgânicos, bem como a predisposição ao seu consumo não está relacionado as pessoas de maior poder aquisitivo. O perfil aqui obtido não é coerente ao observado por Rucinski; Brandenburg (2000) que verificaram em Curitiba/PR que o consumo de alimentos orgânicos está relacionado às pessoas com maior poder aquisitivo. Também, os dados obtidos para a renda familiar neste estudo, não é coerente ao obtido por Cerveira; Castro (1998) em São Paulo, Darolt (2004) em Curitiba/PR e Francisco et al. (2009) em que observaram que a renda predominante era de $\mathrm{R} \$ 3.000,00$ a $\mathrm{R} \$ 4.999,00$ e acima de $\mathrm{R} \$$ $8.000,00$.

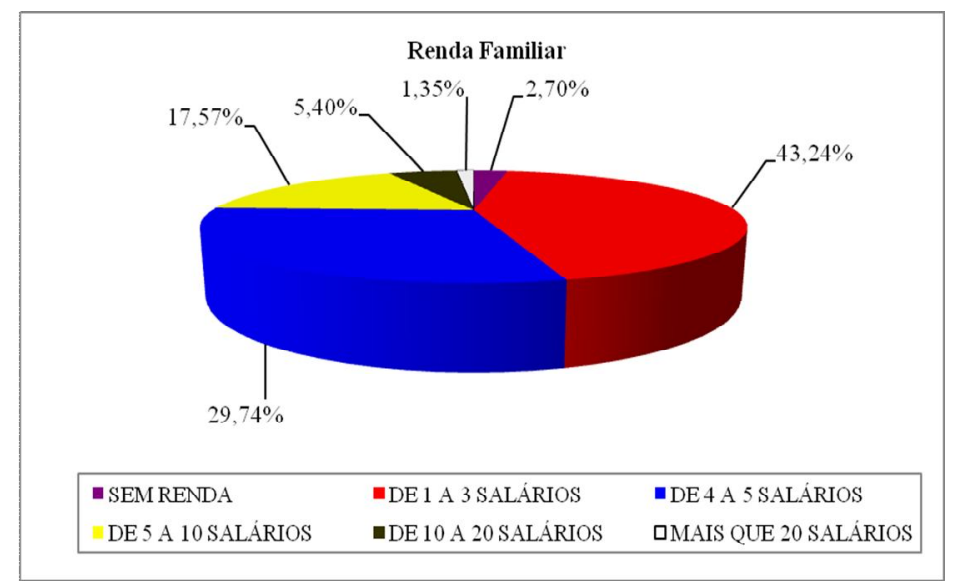

Figura 3: Renda familiar. 


\section{Preocupação com sua alimentação e da família}

Quando foram questionados sobre a preocupação com a alimentação familiar ou a sua, dos entrevistados 94,5 \% responderam que se preocupam com a alimentação da família e 91,89\% com a sua (Figura 4) e citaram que esta preocupação é devido a terem uma dieta mais equilibrada em nome de uma melhor qualidade de vida e saúde e por acharem que os produtos orgânicos é uma alternativa de consumir produtos naturais.
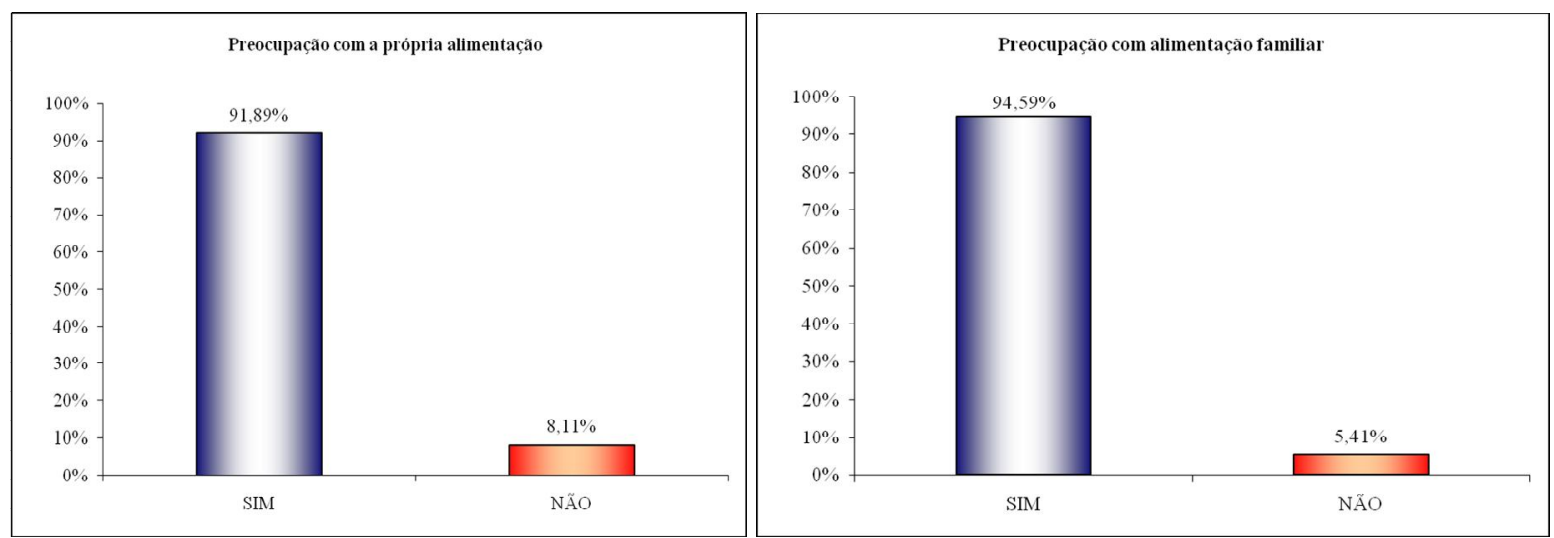

Figura 4: Preocupação com própria alimentação e alimentação da família.

\section{Se já tinham ouvido falar de produtos orgânicos e por qual meio de comunicação}

Ao serem questionados se já tinham ouvido falar de produtos orgânicos, 93,24\% responderam que sim (Figura 5). Dentre os meios que divulgam os produtos orgânicos, a televisão foi citada por $48 \%$ das pessoas entrevistadas. Os dados apresentados na Figura 5 mostram a falta de uma divulgação uniforme sobre produtos orgânicos, e que o meio de comunicação televisão influenciou a maioria dos consumidores.

Com relação a terem ouvido sobre produtos orgânicos, os resultados aqui obtidos são semelhantes aos encontrados por Pimenta et al. (2009) ao estudarem a percepção dos consumidores de produtos orgânicos na região de Maringá/ PR.
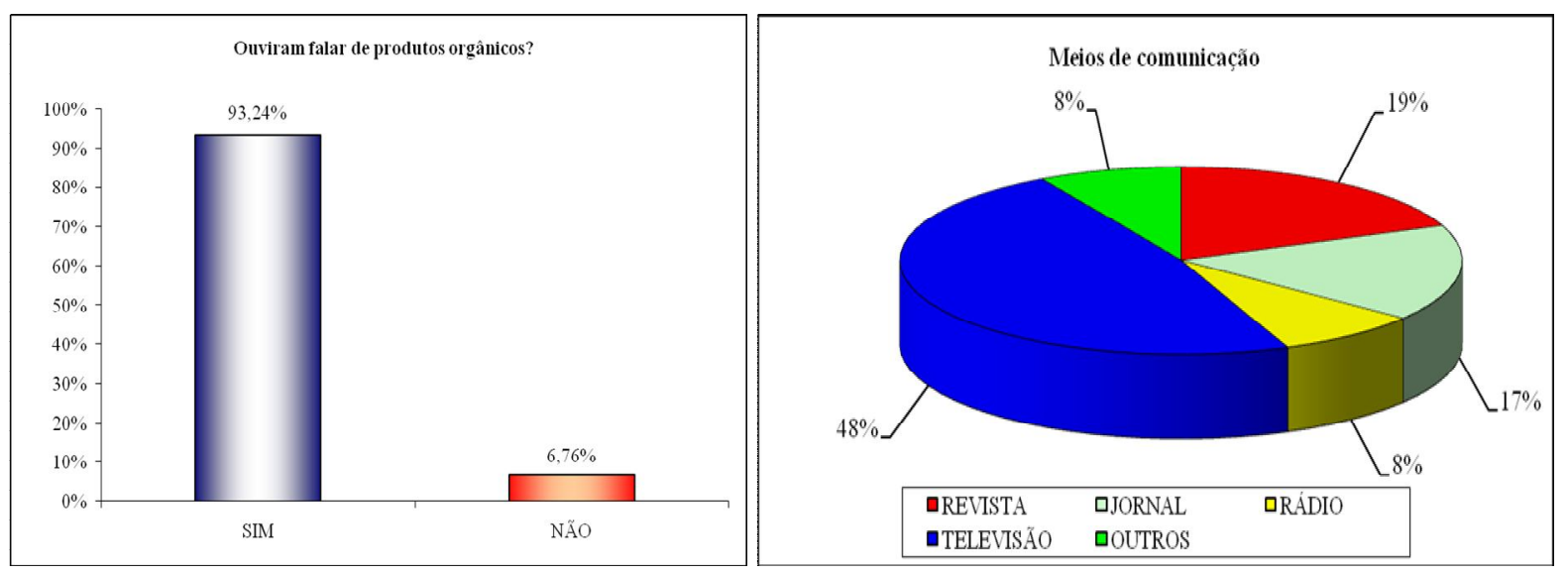

Figura 5: Se tinham ouvido falar de produtos orgânicos e em qual meio de comunicação. 


\section{Definição de produtos orgânicos e informações rotulares}

Apesar de serem compradores ou potenciais compradores de produtos orgânicos, somente $71,62 \%$ responderam que sabem a definição de produto orgânico e 54,05\% responderam que acham que falta informação sobre os produtos (Figura 6). Todos responderam que as informações rotulares atuais são insuficientes para que as pessoas diferenciem produtos orgânicos dos produtos tradicionais, bem como ocorre à falta de benefícios que os mesmos podem ocasionar às pessoas.
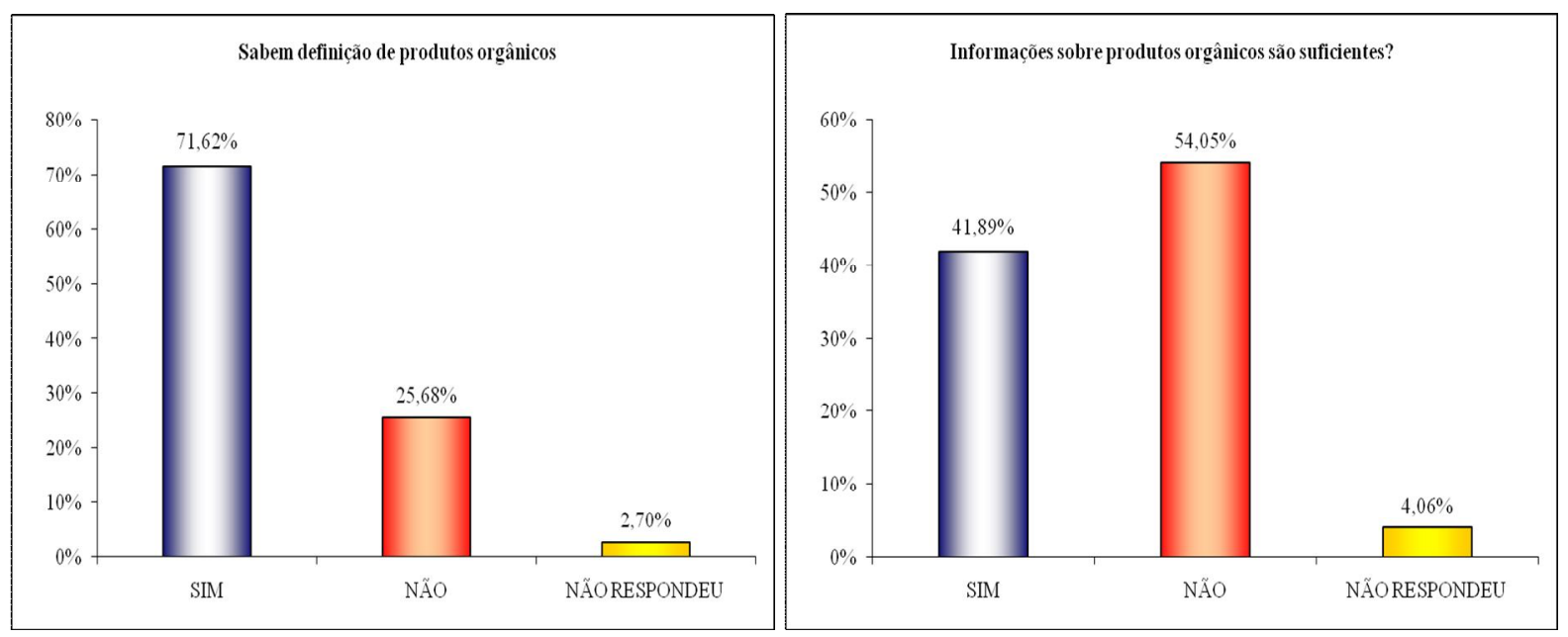

Figura 6: Se os consumidores sabem a definição de produtos orgânicos e se as informações rotulares.

\section{Aquisição de produtos orgânicos e local de aquisição}

Pelos dados graficados na Figura 7, pode-se verificar que $72,97 \%$ já compraram produtos orgânicos e que os locais de compra preferidos são direto do produtor $(41,46 \%)$, seguido pelos supermercados (30,49\%). Também, várias das pessoas entrevistadas falaram que ao adquirirem os alimentos orgânicos nos supermercados não tem certeza se são mesmos, pois não existem muitas informações nas gôndolas, mas mesmo assim pode-se verificar que o supermercado foi o segundo local mais cotado de compra de produtos orgânicos. No estudo realizado por Pimenta et al. (2009) o supermercado também foi indicado como local de compra de produtos orgânicos, apesar de que nesses locais os preços tendem a ser mais elevado. 

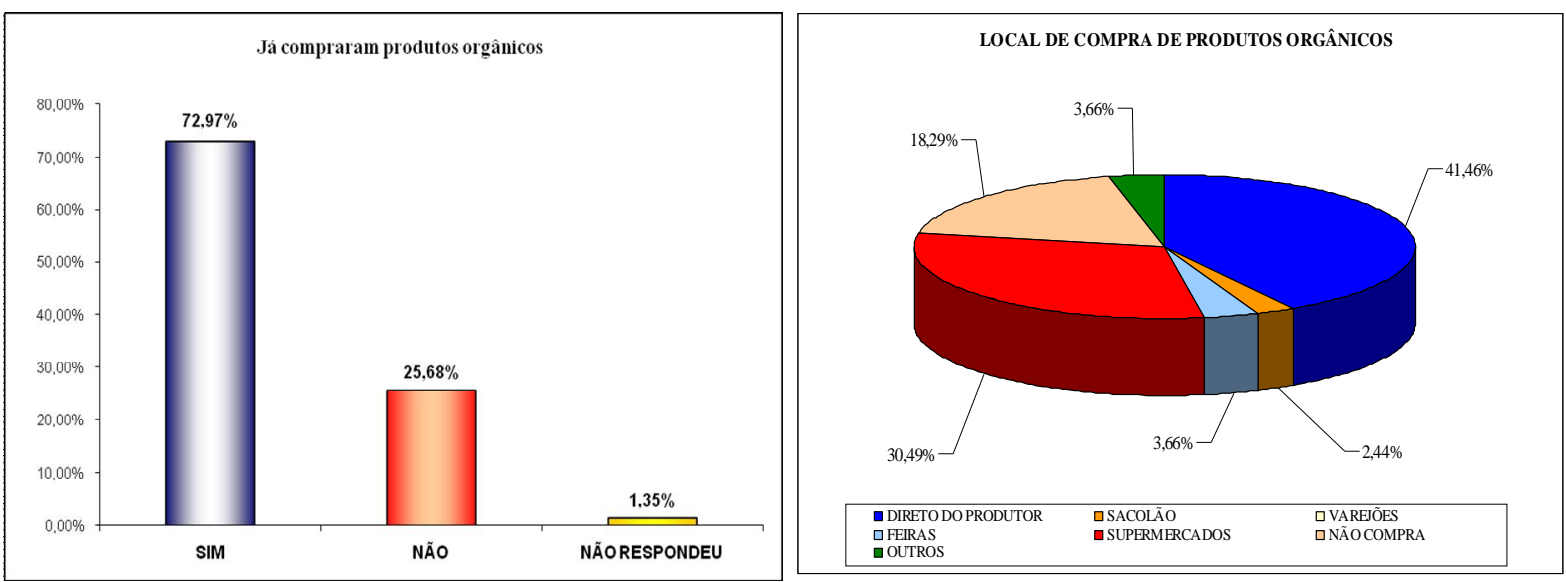

Figura 7: Já compraram produtos orgânicos e qual o local.

\section{Facilidade de compra}

Dos entrevistados, 43,24\% responderam que acham fácil a aquisição dos produtos orgânicos, enquanto que 40,54\% acham difícil (Figura 8). Todos os entrevistados foram unânimes em responder que às vezes tem certa dificuldade em encontrar produtos orgânicos pela falta de informação nos locais de compra.

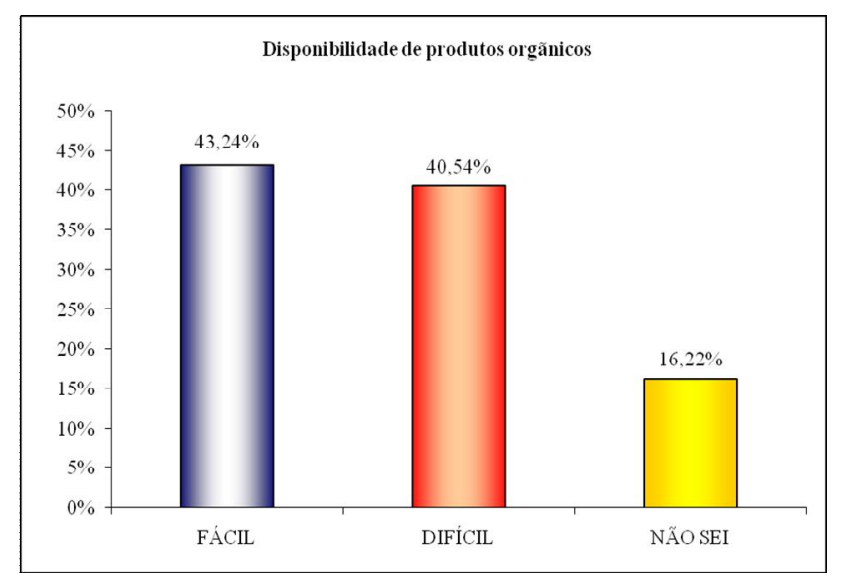

Figura 8: Acesso a compra de produtos orgânicos.

\section{Consumo de produtos orgânicos}

Quanto ao consumo de produtos orgânicos, 78,38\% afirmaram que consomem alimentos orgânicos, e 20,27\% responderam que não (Figura 9). Os que responderam que não consomem, citaram que pretendem consumir. 


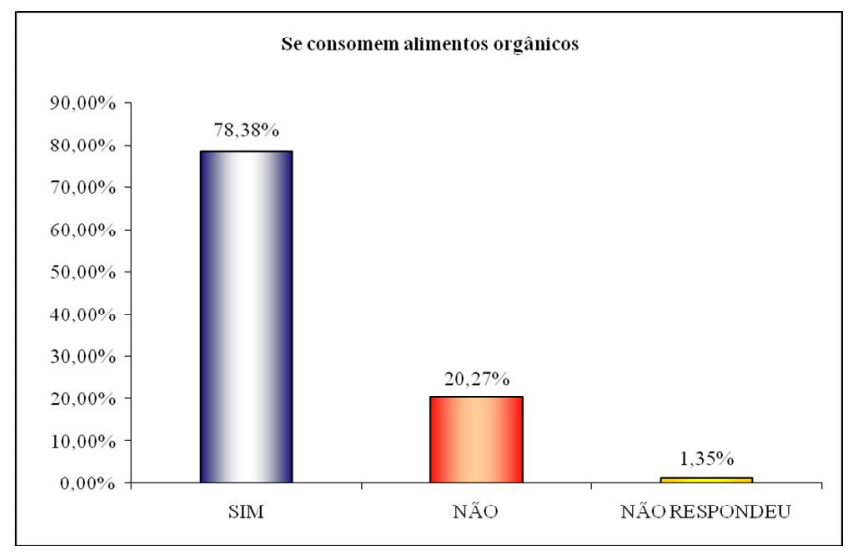

Figura 9: Consome alimentos orgânicos.

\section{Frequência de consumo de produtos orgânicos}

Quanto à frequiência de consumo de produtos orgânicos, 48,65\% responderam que consomem sempre que podem, $20,27 \%$ que consomem uma vez por semana, $14,86 \%$ consomem raramente (Figura 10). Resultados este não coerente ao encontrado por Pimenta et al. (2009), de que 33,3\% dos entrevistados responderam que consomem alimentos orgânicos com freqüência e $28 \%$ responderam que não consomem.

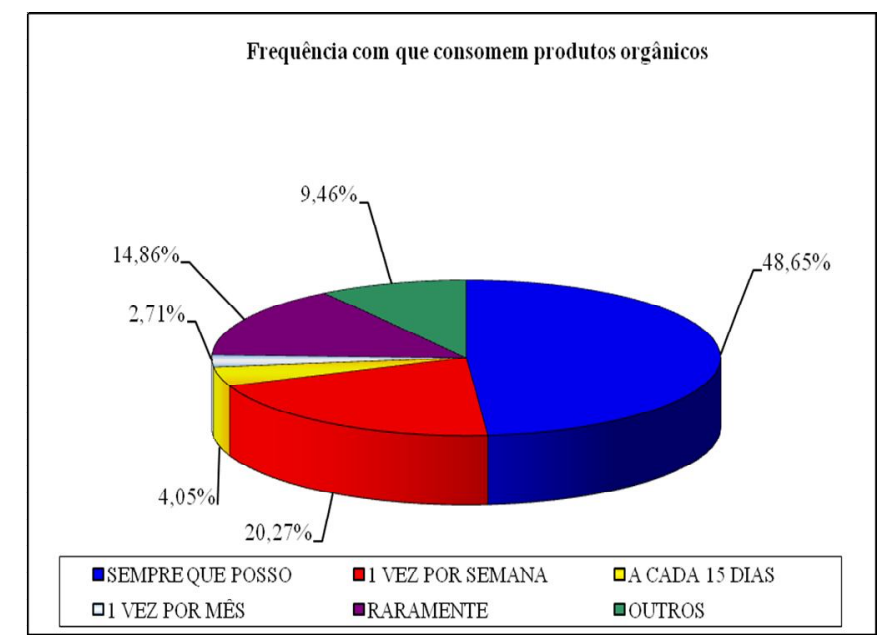

Figura 10: Freqüência de consumo de produtos orgânicos.

\section{Motivos de consumo}

Os motivos determinantes do consumo elencados pelos entrevistados são semelhantes aos elencados em outros estudos de perfil do consumidor. Preponderaram os fatores busca por alimentos mais saudáveis $(15,15 \%)$, para melhoria da qualidade de vida (11,69\%), por entenderem ser um produto natural $(10,82 \%)$, para contribuir com a preservação da saúde $(10,39 \%)$, entre outros (Figura 11). Também, 10,39\% dos entrevistados responderam que os consomem por ser um produto mais saudável e saboroso e $9,05 \%$ para preservar a saúde e o 
meio ambiente (Figura 11).

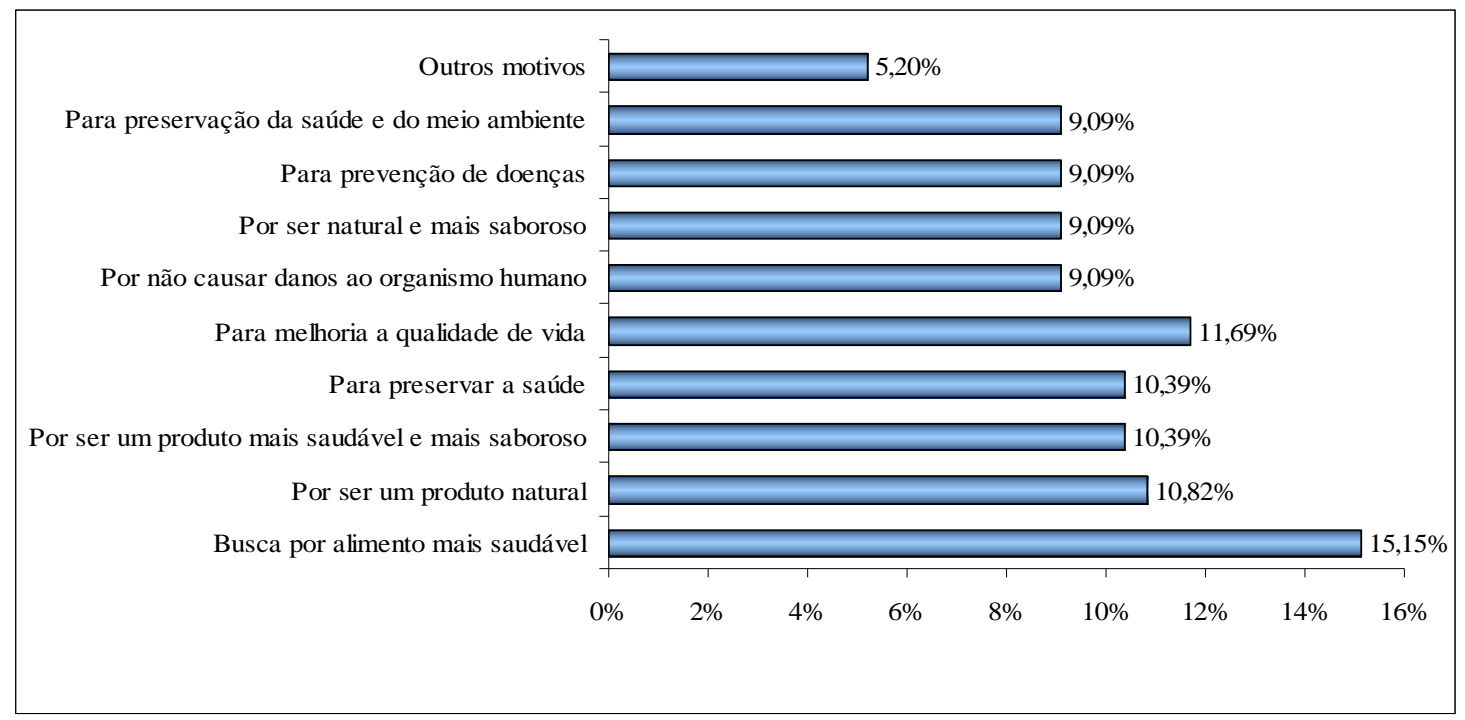

Figura 11: Motivos de consumo de produtos orgânicos.

\section{Aumento do consumo de produtos orgânicos e o grau de confiança}

Através dos dados graficados na Figura 12, pode-se verificar que do total de pessoas que consomem produtos orgânicos $67,57 \%$ pensam em aumentar o consumo e 18,92\% não sabem. Como forma de aumentar o consumo, os entrevistados apontaram como sugestão: diminuição de preço, aumento de divulgação, melhor regularidade na oferta e instituição da obrigatoriedade da certificação, entre outro itens.

Também pela Figura 12, pode-se verificar que 47,36\% do publico alvo são confiante nos produtos orgânicos e 21, $62 \%$ são muito confiantes. Estes valores podem ser atribuídos ao fato levantado pelos mesmos que é a falta de informação nos locais de venda e pela falta de informações rotulares.
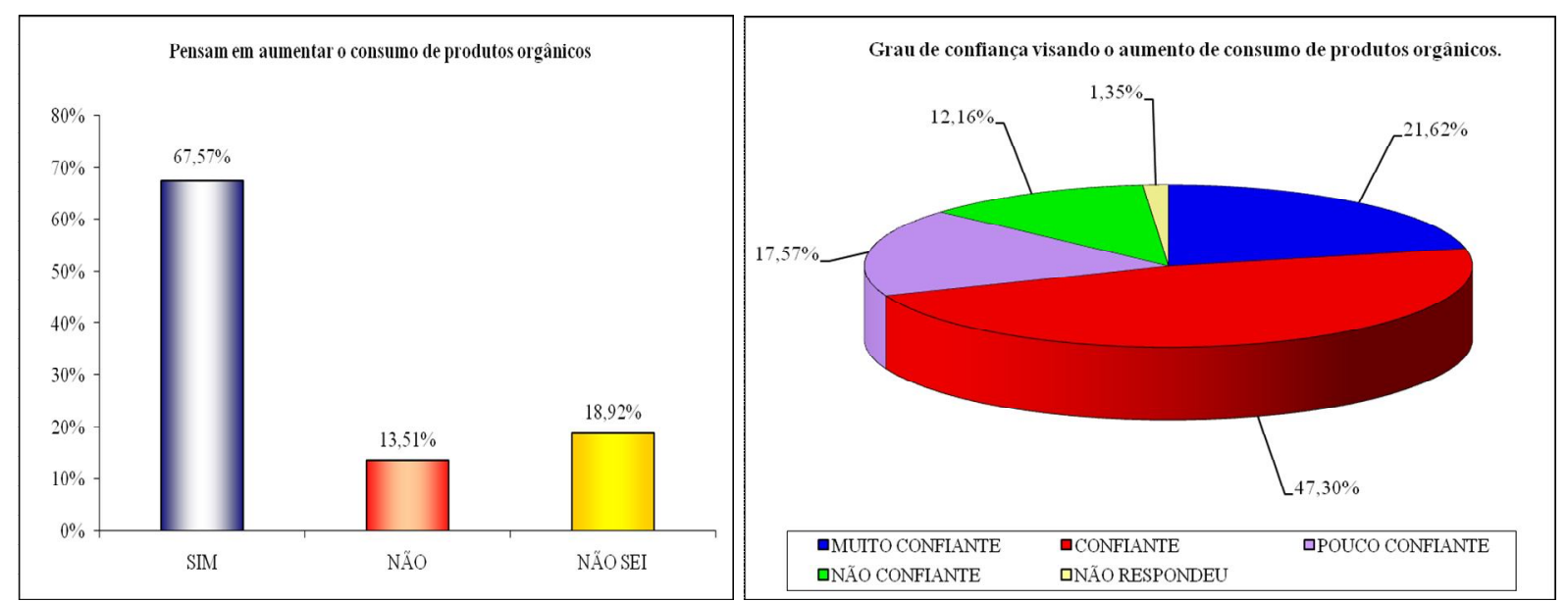

Figura 12: Aumento no consumo de produtos orgânicos e grau de confiança. 


\section{CONCLUSÃO}

Os resultados obtidos no presente estudo indicam que consumidores ou potenciais consumidores de produtos orgânicos predominante é mulher, independente do grau de escolaridade e classe social, e que este consumo está relacionado mais a busca por uma melhor qualidade alimentar, pela saúde, por melhoria de qualidade de vida e por produtos mais saborosos.

A predisposição dos consumidores, visualizada neste estudo, em aumentar seu consumo pode incentivar o mercado, pois proporcionará novas fronteiras rumo a uma expansão dos produtos, conscientizando a baixa de preços e aumento da demanda de mão de obra.

Também, este estudo contribui para a caracterização do consumidor de um importante setor do mercado, que tem passado por grande expansão ao longo dos últimos anos e tende reforçar-se cada vez mais, o que levara a necessidade de novos estudos.

Para finalizar pode-se citar que o grupo de pessoas que consomem produtos orgânicos esta imergindo e que o entrave para o seu aumento é a falta de informações em locais de venda e nos rótulos.

\section{REFERÊNCIAS}

ARCHANJO, L.R; BRITO, K.F.W; SAUERBECK, S. Alimentos orgânicos em Curitiba: consumo e significado. Cadernos de Debate, v.8., p. 1-6, 2001.

CERVEIRA, R.; CASTRO, M. C. Perfil sócio-econômico dos consumidores de produtos orgânicos da cidade de São Paulo. 1998. Disponível em: <http://www.megaagro.com.br/ organica/perfil_um.asp>. Acesso em: 14 out 2010.

CUENCA, M.A.G. et al., Perfil do consumidor e do consumo de produtos orgânicos no Rio Grande do Norte. Boletim informativo EMBRAPA. Aracaju/SE, Out. 2007.

DAROLT, M. R. Porque os alimentos orgânicos são mais caros. 2001. Disponível em: <http://www.planetaorganico.com.br/trabdarmais.htm>. Acesso em: 08 jun. 2010.

DAROLT, M. R. Vantagens e desvantagens dos principias canais de comercialização de produtos orgânicos. 2003. Disponível em:

<http//www.ibd.com.br/arquivos/artigos/comercialização.htm>. Acesso em: 15 maio 2010.

DAROLT, M. R. O papel do consumidor no mercado de produtos orgânicos. 2004. Disponivel em: <http://www.planetaorganico.com.br/trabdarolt1.htm>. Acesso em: 13 out 2010. 
FOLHA. Venda de alimento orgânico aumenta até 40\% no varejo. 12 de maio de 2009. Diponivel em: <http://www1.folha.uol.com.br/fsp/dinheiro/fi1205200936.htm>. Acesso em: 13 out 2010.

FRANCISCO, E. S. et al. Comportamento do consumidor na compra de produtos orgânicos. In: SEMINARIOS EM ADMINISTRAÇÃO, 12, São Paulo/SP, 27 e 28 de agosto de 2009. Anais... São Paulo: SEMEAD, 2009.

KARAM, K. F.; ZOLDAN, P. Dinâmica e Estratégias da comercialização de produtos orgânicos em Santa Catarina. Florianópolis/ SC: Instituto CEPA, 2004. p. 1-19.

MALHOTRA, N.K. Pesquisa de marketing: uma orientação aplicada. 3. ed. Porto Alegre: Bookman, 2001.

MOMESSO, C.M.V.; ROEL, A.R.; FAVARO, S.P. Levantamento do Potencial de comercialização de produtos orgânicos para o estado de Mato Grosso do Sul. Interações, Campo Grande, MT, v.10, n.1, p.55-62, jan./jun. 2009.

ORMOND, J. G.P et al. Agricultura orgânica: quando passado é futuro. BNDES Setorial, Rio de Janeiro, n.15 p. 17, mar. 2002.

PEREIRA, P. R.; ABICHT, A. M.; CEOLIN, A. C.; CORREA, A. F.; SILVA, T. N. A subvenção de orgânicos no Brasil e na união européia sob a ótica da visão baseada em recursos. In: CONGRESSO DA SOCIEDADE BRASILEIRA DE ECONOMIA, ADMINISTRAÇÃO E SOCIOLOGIA RURAL, 46, Rio Branco/ AC, 20 a 23 jul. 2008. Anais... Rio Branco: SOBER, 2008. p.1-12.

PIMENTA, V. P et al.; Percepção dos consumidores quanto aos produtos orgânicos na região de Maringá/PR. Revista Brasileira de Agroecologia. n.2, p 2903-2907, nov.2009.

RUCINSKI, J.; BRANDENBURG, A. Consumidores de alimentos orgânicos em Curitiba. Associação nacional de pós-graduação e pesquisa em ambiente e sociedade (ANPPAS). 2000. Disponível em: <http://www.anppas.org.br〉. Acesso em 30 abr. 2010.

SCHULTZ, G.; NASCIMENTO, L. F. M.; PEDROSO, E. A. As cadeias produtivas de alimentos orgânicos do município de Porto Alegre/ RS frente à evolução das demandas do mercado: Lógica de Produção e/ou distribuição. 2002. 185f. Dissertação (Mestrado em Agronegócio). Universidade Federal do Rio Grande do Sul.

SOUZA, M. C. M. Produtos Orgânicos. In: ZYLBERSZTAJN, D.; NEVES, M. F. (Orgs.) Economia e gestão dos negócios agroalimentares. São Paulo: Pioneira, 2000. p. 385-401.

STEFANO, N; NETO, A. C.; GODOY L.P. Explorando conceitos e modelos sobre o processo de decisão de compra do consumidor em função da mudança de hábito alimentar. In: CONGRESSO NACIONAL DE EXCELÊNCIA EM GESTÃO, 4, Niterói/ RJ, 31 jul. a 02 ago. 2008. Anais... Niterói: CNEG, 2008. p. 1-20.

WILLER, H.; YUSSEFI, M. The World of Organic Agriculture- Statistics and Emerging Trends 2006. International Federation of Organic Agriculture Movements- IFOAM, 2006. 21p. Disponível em: <http://orgprints.org/5161/01/yussefi-2006overview.pdf.> Acesso em 30 abr.2010. 